\title{
Modelling patch dynamics on rocky shores using deterministic cellular automata
}

\author{
M. T. Burrows ${ }^{1, *}$, S. J. Hawkins ${ }^{2,3}$ \\ 'Dunstafinage Marine Laboratory, PO Box 3, Oban, Argyll PA34 4AD, United Kingdom \\ ${ }^{2}$ Port Erin Marine Laboratory, University of Liverpool, Port Erin, Isle of Man IM9 6JA, United Kingdom \\ ${ }^{3}$ Biodiversity and Ecology Division, School of Biological Sciences, University of Southampton, Bassett Crescent East, \\ Southampton SO16 7PX, United Kingdom
}

\begin{abstract}
A model of biologically driven patchiness in the Fucus-limpet-barnacle mosaic on rocky shores was developed using deterministic cellular automata. The model is based on interconnected small areas of approximately 1 limpet foraging diameter $(1 \mathrm{~m})$. Five states are recognised, which represent stages in the natural cycle of development of patches: (1) dense barnacle cover with no limpets; (2) patches of young Fucus plants (escapes); (3) aggregations of limpets under ageing fucoids: (4) limpet aggregations from which fucoids have been lost; and (5) areas from which limpets have dispersed. Rules governing the transitions between these states were derived from experimental studies and qualitative models. These rules are based on the abundance of fucoids and limpets in adjoining areas and the current state of the areas themselves. Spatial patterns and spatial dynamics produced are sensitive to the sets of rules considered and the criteria for local dependence of state transitions. Certain conditions result in large stable patches of limpet aggregations or fucoids that are resistant to invasion by the other. Different conditions create large-scale areas of synchrony of patch cycling in which waves of areas in the same state propagate from local foci. These conditions produce limited grid-scale cycling in the abundance of fucoids, barnacles and limpets. Despite the qualitative nature of the model and the patterns and dynamics produced, its heuristic value remains. Local dependence of the fate of small areas requires further experimental study before the dependence of larger-scale fluctuations on these small-scale interactions can be established.
\end{abstract}

KEY WORDS: Limpets - Fucoids - Patch dynamics - Cellular automata - Rocky shore communities Herbivore aggregation

\section{INTRODUCTION}

Patchiness is a fundamental property of most communities (see articles in Pickett \& White 1985 and Shorrocks \& Swingland 1990). In marine ecosystems patchiness can be observed on various spatial scales: on the broad scale of the ocean pelagic systems $(1 \mathrm{~km}$ to $100 \mathrm{~km}$ scale in krill; Mangel 1994) to smaller-scale patchiness in benthic communities (e.g. Morrisey et al. 1992). At this small scale, static patchiness can result from the direct and indirect effects of micro-habitat variations in abiotic environmental factors (Lubchenco 1983). More dynamic patchiness can result from un-

·E-mail:mtb@wop.nerc.ac.uk evenly distributed physical disturbance, initiating a mosaic of small-scale successional events (Sousa 1979). Dynamic patchiness in uniform environments can be caused by biological factors such as stochastic recruitment events (Caffey 1985, Menge 1991) and foraging patterns resulting in uneven grazing and predation (Fairweather 1988a, Hughes \& Burrows 1993).

Rocky shores are good systems for experimental studies of the causes of distribution patterns and community structure, particularly patchiness on the readily observable $10 \mathrm{~cm}$ to $1 \mathrm{~m}$ scale (e.g. Paine \& Levin 1981). Recent studies have shown that spatial variation in abundance of rocky shore species is most evident at 2 length scales. Biological variation at the scale of $100 \mathrm{~s}$ of $\mathrm{m}$ to several $\mathrm{km}$ (between shores) is generated by variation in recruitment (Underwood \& Chapman 
1996) or physical conditions such as wave exposure, salinity and substratum type. Variation also peaks at a smaller scale from several $\mathrm{cm}$ to less than $2 \mathrm{~m}$ and is caused by behavioural responses and settlement in relation to micro-habitat features such as cracks and crevices (Archambault \& Bourget 1996, Underwood \& Chapman 1996). The scale of this variation also matches observed patch sizes for Fucus clumps on moderately exposed rocky shores (Johnson et al. 1997). On topographically uniform shores these algal patches are thought to be examples of spatial self-organised patterns generated by the interaction of Fucus clumps and limpet grazers. This phenomenon is the subject of the model described here.

Spatial modelling of populations and communities has developed rapidly since the late 1980 s. The main techniques used include reaction-diffusion equations (Lewis 1994, Sherratt et al. 1997), coupled map lattices (Hassell et al. 1991) and cellular automata (Wolfram 1986). Reaction-diffusion equations embody dispersal and aggregative processes as partial differential equations and are an attractive option, allowing analytical solutions that predict spatial patterns and dynamics in a wide variety of circumstances. Coupled map lattices, as the name suggests, divide space into discrete nodes that are connected to their neighbours. At each node, population dynamics of 1 or more species often follow classical formulations such as the Nicholson-Bailey host-parasitoid model (Comins et al. 1992), while dispersal processes exchange populations between neighbouring nodes according to simple diffusion (Comins et al. 1992) or density-dependent dispersal (Rohani \& Miramontes 1995). Cellular automata (CAs; see Ermentrout \& Edelstein-Keshet 1993 for review) similarly consist of connected nodes or cells, but express the state of each node as one of a number of discrete categories representing recognisable ecological states. Changes in cell states depend on the states of the surrounding cells in either a probabilistic or deterministic manner. Cellular automata thus have the advantage over other techniques in that expert knowledge on underlying biological processes can be incorporated as 'transition rules' without the need for extensive parameterization (Jeltsch et al. 1996). It is therefore the most appropriate methodology for formalising the current conceptual model of the dynamics of algal patches on rocky shores. Despite the apparent oversimplification of the CA approach, when alternative spatial modelling techniques (including CAs) have been applied to the same ecological system, very similar predictions of spatial dynamics have been produced (van der Laan et al. 1995, Sherratt et al. 1997).

While reaction-diffusion equations and coupled map lattices have mainly been used in theoretical studies of ecological processes in a spatial context (e.g. Rohani \&
Miramontes 1995), cellular automata have largely been used in specific applications: from the dynamics of pest dispersal (Zhou \& Liebhold 1995) to vegetation patterns in arid environments (Jeltsch et al. 1996, Dunkerly 1997) and the dynamics of forest clearings (Jeltsch \& Wissel 1994, Hendry \& McGlade 1995). Most of these CA models have probabilistic transition rules based on observations of local spatial dependence and spatial patterns, with the result that models have been closely allied to field predictions.

In this paper we take advantage of the experience gained from more than $45 \mathrm{yr}$ of observation and experiment (see Southward 1964, Hawkins et al. 1992 for reviews) on a moderately exposed Manx (Isle of Man, United Kingdom) shore to construct simple rules for modelling the community there using deterministic cellular automata. Cells in the model represent small areas $\left(<1 \mathrm{~m}^{2}\right)$ of substratum in discrete states representing the typical cycle of events seen in the development of biological patchiness. Whether a change in state occurs in an area depends on the sum of the abundance of different community elements (barnacles, limpets, fucoids) in adjacent areas compared with predefined thresholds. First, the system under study is briefly reviewed and qualitative models and interaction webs summarised. These ideas are used to construct formal sets of rules for model building. The model is then run under different sets of rules and parameter values. The results of the model are compared with data from the field. Key areas of interest and uncertainty are highlighted to formulate hypotheses for testing in natural conditions.

\section{Fucus-limpet-barnacle mosaic cycle}

Mid-shore regions of moderately exposed rocky shores in Britain are often characterised by a patchy community (Lewis 1964). It is common to find a temporally variable mosaic of fucoids, barnacles and bare rock, interspersed with limpets, dogwhelks and anemones. Port St. Mary Ledges and other limestone shores on the south coast of the Isle of Man are wellstudied examples (Southward 1953). Long-term studies (Southward 1953, Hawkins \& Hartnoll 1983a, Hartnoll \& Hawkins 1985) have highlighted the dynamic nature of the patchiness. Fig. 1 summarises the fluctuations over $17 \mathrm{yr}$ in a $2 \mathrm{~m}$ by $1 \mathrm{~m}$ area, containing a maximum of 3 to 4 patches of Fucus. This area has been both completely bare and nearly completely covered by fucoids but most of the time fucoid cover was between 20 and $50 \%$. Any increases in fucoid cover were followed by increases of juvenile and adult limpets, dogwhelks and anemones. The last 2 rapidly disappeared when Fucus clumps were lost. Adult limpets 


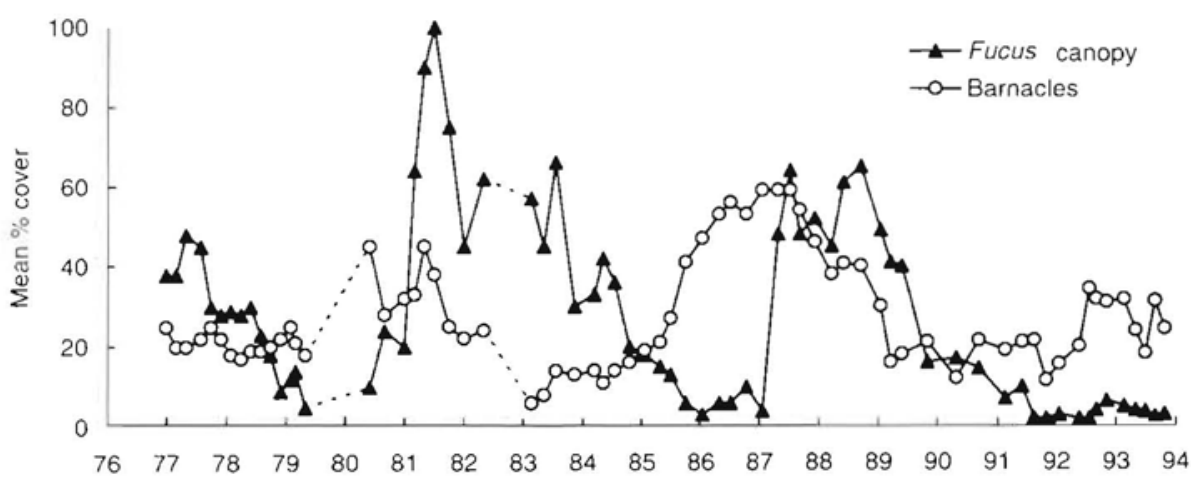

Fig. 1. Changes in abundance of (a) Fucus and barnacles and (b) juvenile and adult limpets in a $2 \mathrm{~m}$ by $1 \mathrm{~m}$ area in the mid-shore region at Port St. Mary Ledges, Isle of Man, United Kingdom, over $17 \mathrm{yr}$

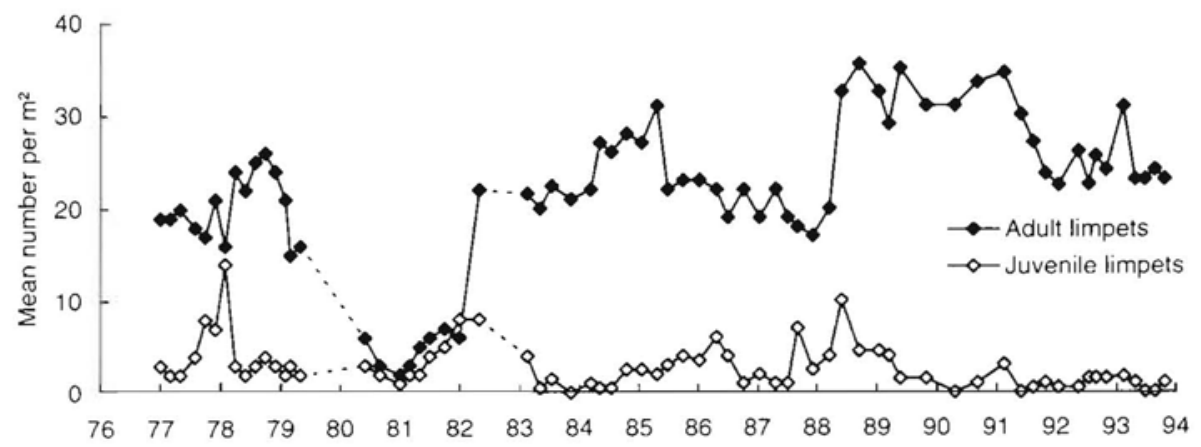

remained for some time afterwards but their numbers tended to decrease when Fucus cover was low. Wholeshore photographs and qualitative observations over the last $15 \mathrm{yr}$ have shown that such local events occur all over the mid-shore region.

Pioneering studies involving large-scale experimental removal of limpets demonstrated the importance of interactions between the limpets, fucoids and barnacles in structuring these communities (Jones 1948, Lodge 1948, Burrows \& Lodge 1950, Southward 1956, 1964). More recently, a further series of experiments have defined the smaller-scale interactions in this mosaic (see Hawkins \& Hartnoll 1983b, Hawkins et al. 1992, for reviews). A reduction in the number of limpets by predation or physical disturbance, or a change in their pattern of distribution, can result in localised areas of low grazing intensity. Patches of Fucus germlings (escapes) arise in the ungrazed areas, particularly if covered by barnacles (Hawkins 1981a, b). Intensive mapping of mid-shore areas has allowed analysis of the spatial pattern of these escapes in relation to the local density of grazing limpets (Johnson et al. 1997). The likelihood of an escape decreases with the number of limpets in the same and neighbouring areas, consistent with low grazing as the main promoter of escapes.

Qualitative observations suggest that juvenile and adult limpets, together with dogwhelks and anemones, aggregate quite rapidly in the shelter provided by newly established clumps (Hawkins \& Hartnoll 1983a,
Hartnoll \& Hawkins 1985). After 2 or 3 yr these clumps of Fucus are gradually thinned as the plants get larger. This occurs in stormy weather when increased drag and insecure anchorage of those clumps growing on barnacles results in the removal of whole plants (Barnes \& Topinka 1969). Loss of Fucus plants so anchored tears barnacles out of the surrounding matrix of fused barnacle shells. Fucus plants fixed to bare rock can also be weakened by grazing of limpets on the stipe (Southward \& Southward 1978). Barnacles under the Fucus plants are also eaten by the sheltering dogwhelks. New settlement of barnacles under the Fucus clumps is prevented primarily by sweeping of the algal fronds but limpet bulldozing may also be important (Hawkins 1983). Eventually, the clump of Fucus disappears, leaving a group of limpets in an area of reduced barnacle cover or bare rock.

Groups of limpets formed under Fucus clumps may persist for some time after the plants disappear. This may enable new Fucus clumps to arise in areas of lower grazing pressure between the limpet clusters. These areas tend to have denser barnacle cover that also reduces the effectiveness of limpet grazing (Hawkins 1981b). It has been proposed that fluctuations in fucoid recruitment either accelerate or retard the cycle of events by promoting or reducing the likelihood of escapes from grazing (Hartnoll \& Hawkins 1985). Escapes are more likely in years of increased Fucus reproductive output and settlement. Dense barnacle 


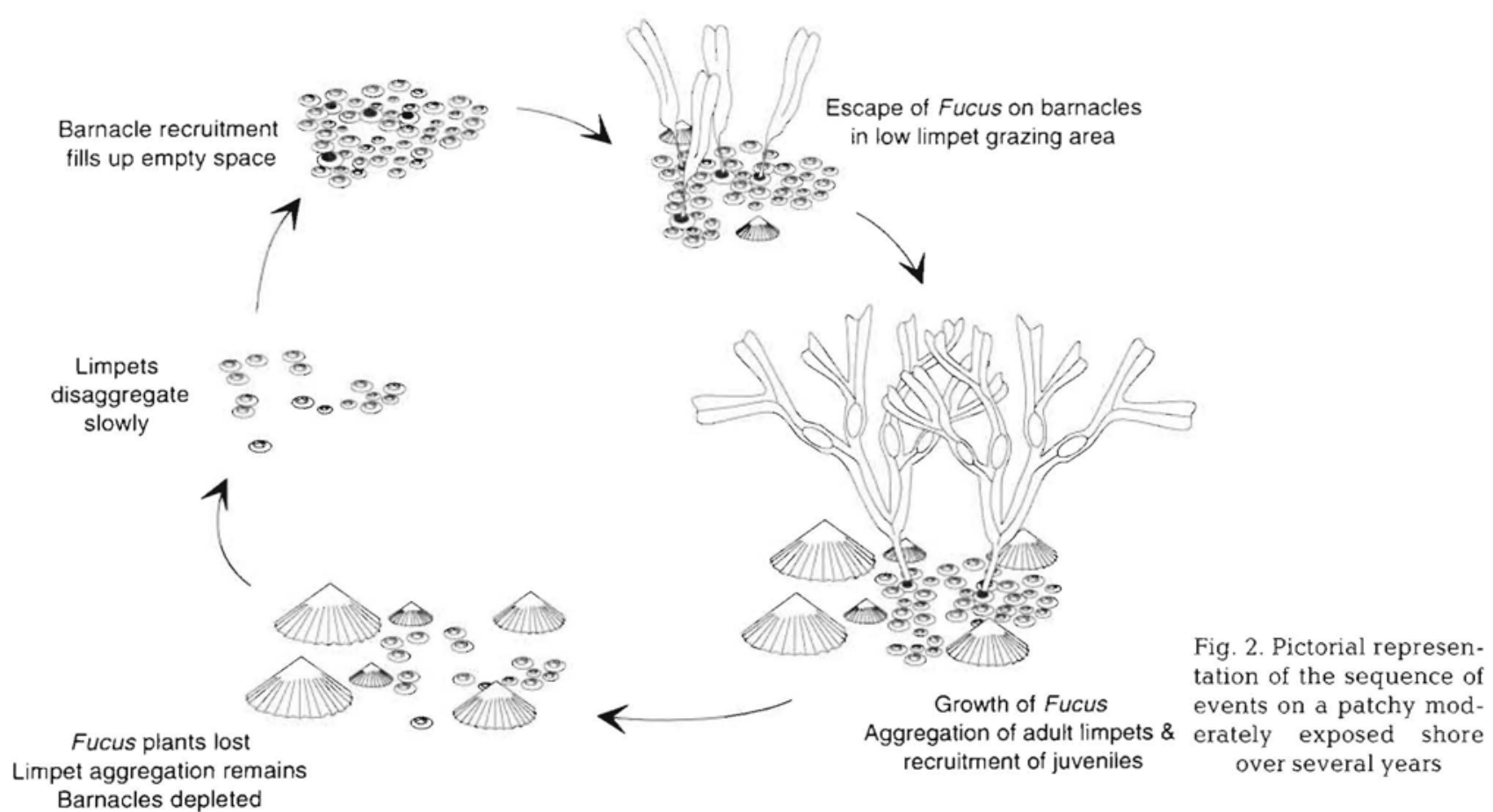

settlement also promotes fucoid escapes in subsequent years by reducing the effectiveness of limpet foraging (Hawkins \& Hartnoll 1982b, Lubchenco 1983). Poor limpet recruitment facilitates escapes, while good limpet recruitment inhibits escapes.

Qualitative models (Southward 1964, Southward \& Southward 1978, Hawkins \& Hartnoll 1983a, Hartnoll \& Hawkins 1985) have been developed which propose that patchiness on Northeast Atlantic moderately exposed rocky shores is generated and maintained by a combination of the above intrinsic deterministic processes and stochastic events (see Fig. 2). These models have highlighted the importance of the aggregation of limpets, the dominant consumers, in providing the conditions necessary for Fucus escapes. In this paper, the deterministic rules for local interaction developed from the earlier models are placed in spatial models, to ascertain the consequences for local- and broaderscale community dynamics and spatial patterns.

\section{METHODS}

Cellular automata of varying dimension were used (typically $25 \times 25$ cells, with a minimum size of $10 \times 10$ and maximum of $100 \times 100$ ). Each cell represents an area of the shore of approximately 1 foraging diameter of an adult limpet ( $1 \mathrm{~m}$; Hartnoll \& Wright 1977). The number of cells in the grid rarely has an effect on the outcome of a simulation, but does affect the magnitude of grid-scale changes relative to the potential total abundance of community elements in the grid. Edge effects are dealt with by use of a toroidal grid: the top edge abuts onto the bottom edge, and the left edge upon the right. Cells in the bottom row are influenced by those in the top row and similarly for left and right edges.

The states involved in the model were based on a simplified set of those identified by Hawkins \& Hartnoll (1983b), in part based on Burrows \& Lodge (1950). These represent recognised stages of the cycle of changes typically seen in the fate of patches on moderately exposed rocky shores (Hartnoll \& Hawkins 1985; Table 1).

The 5 cell states $\left(C_{i}\right)$ form a cycle in which the transition from one state to the next depends upon the states of the neighbouring cells. Each state contains a fixed abundance of limpets, barnacles and fucoids. This was represented in the model by integer scores from 0 to 2 for limpets and barnacles, and 0 to 1 for fucoids (Table 1). Using only presence/absence scores for limpets in model simulations produced similar patterns and dynamics, but the greater range adopted here better represented the differences in resulting grazing intensity between small juveniles under new escapes and mature adults under larger plants.

The influence of local conditions on any particular cell is represented by the sums of the scores for barnacle, limpet and fucoid abundance (Table 1) in the 8 adjacent cells ( $\Sigma f_{j}$ in Eq. 1 below). An effect of local abundance on the change in state of a particular cell occurs if the sum of the scores in adjacent cells exceeds a threshold value $\left[F_{C}\right.$ for fucoids, $L_{C}$ for limpets; a 'totalistic' (Wolfram 1986) or 'voting-rule' (Childress et al. 1996) model]. 
Table 1. The 5 states of the patch cycle and the dependence of transitions between states on neighbouring conditions. Integer scores for the abundance of limpets $\left(l_{j}\right)$, fucoids $\left(f_{i}\right)$ and barnacles $\left(b_{i}\right)$ are shown for each state. Alternative rules for transitions from state 2 to state 3 (aggregation: [1], [1a], [1b], [2]) and from state 4 to state 5 (disaggregation: [3], [3a]. [3b], [4]) are based on different dependencies on the sum of scores of fucoids $\left(\Sigma f_{t}\right)$ or limpets $\left(\Sigma l_{1}\right)$ in the 8 adjoining cells. Critical threshold values of local abundance of fucoids and limpets are given by the variables $F_{\mathrm{C}}$ and $L_{\mathrm{C}}$

\begin{tabular}{|c|c|c|c|c|c|c|c|c|}
\hline State $C_{\text {, }}$ & l, & $f_{\text {, }}$ & $b$, & Description & \multicolumn{4}{|c|}{ Local dependence of state transitions } \\
\hline 1 & 0 & 0 & 2 & Dense barnacles, no limpets & - & - & - & - \\
\hline 2 & 1 & 1 & 2 & Fucus escape & - & - & - & - \\
\hline$\nabla$ & & & & $\begin{array}{l}\text { Limpet aggregation under } \\
\text { new clump occurs: }\end{array}$ & $\begin{array}{l}\text { Always } \\
{[2]}\end{array}$ & $\begin{array}{l}\text { When fucoids } \\
\text { are locally } \\
\text { rare [1a] } \\
\sum f_{j}<F_{\mathrm{C}}\end{array}$ & $\begin{array}{l}\text { When limpets } \\
\text { are locally } \\
\text { common [1b] } \\
\sum l_{j}>L_{C}\end{array}$ & $\begin{array}{l}\text { When both } \\
\text { conditions apply } \\
\text { [1] } \quad \sum f_{j}<F_{\mathrm{C}} \\
\text { and } \quad \sum l_{j}>L_{\mathrm{C}}\end{array}$ \\
\hline 3 & 2 & 1 & 1 & Limpets under aging Fucus & - & - & - & - \\
\hline 4 & 2 & 0 & 1 & $\begin{array}{l}\text { Fucus dies, limpet } \\
\text { aggregation remains }\end{array}$ & - & - & - & - \\
\hline$\nabla$ & & & & $\begin{array}{l}\text { Limpet disaggregation from } \\
\text { the site of Fucus plant occurs: }\end{array}$ & $\begin{array}{l}\text { Always } \\
\text { [4] }\end{array}$ & $\begin{array}{l}\text { When fucoids } \\
\text { are locally } \\
\text { common [3] } \\
\Sigma f_{j}>F_{C}\end{array}$ & $\begin{array}{l}\text { When limpets } \\
\text { are locally } \\
\text { rare [3a] } \\
\Sigma l_{j}<L_{C}\end{array}$ & $\begin{array}{l}\text { When both } \\
\text { conditions apply } \\
\text { [3b] } \sum f_{j}>F_{C} \\
\text { and } \sum l_{j}<L_{C}\end{array}$ \\
\hline 5 & 0 & 0 & 1 & Patchy barnacles, no limpets & & & & \\
\hline
\end{tabular}

Two sets of rules were examined (Table 1), the first set governing the aggregation of limpets under new fucoid clumps (state 2 to state 3 ), and the second set governing the disaggregation of limpets from cells in which the Fucus plants have died (state 4 to state 5). Limpet aggregation occurs when fucoids are rare in the surrounding cells (rule [1a]), when limpets are abundant in the surrounding cells (rule [1b]), when both conditions apply (rule [1]), or in every cell in which an escape occurs (rule [2]). Thus in the case of rule [1]:

$$
C_{i}^{\prime}=\left\{\begin{array}{c}
3 \text { if } \sum f_{j}<F_{\mathrm{C}} \text { and } \sum_{j, N} l_{j}>L_{\mathrm{C}} \\
2 \text { otherwise }
\end{array} \mid C_{i}=2\right.
$$

where, for cell $i, C_{i}$ is the current state of the cell, $C_{i}{ }^{\prime}$ is the next state of the cell, and $f_{j}$ and $l_{j}$ are the fucoid and limpet abundance scores in an adjacent cell $j$, which is a member of the set of $\mathrm{N}$ cells (8) next to the current cell $i$. Rules [1a], [1b] and [2] are obtained by progressive relaxation of this condition.

Disaggregation of limpets from a cell in which the Fucus plants have died (state 4 to state 5) may occur only when the surrounding cells have many fucoids and are occupied by a few potentially competing limpets. Thus, the most stringent condition for disaggregation (rule [3b]) can be represented as

$$
C_{i}^{\prime}=\left|\begin{array}{c}
5 \text { if } \sum_{n N} f_{j}<F_{\mathrm{C}} \text { and } \sum_{N N} l_{j}<L_{\mathrm{C}} \\
4 \text { otherwise }
\end{array}\right| C_{i}=4
$$

Other transition rules for limpet disaggregation are again obtained by progressive relaxation of this condition (Table 1).

Effects of variation in thresholds of local effects and the use of different sets of rules were examined in a series of simulations. Threshold values for local abundance were varied between their maximum and minimum values for each type of influencing species (fucoids: $F_{C}=0$ to 8 ; limpets: $L_{C}=0$ to 16 ) for each combination of transition rules considered. Each simulation was run until a stable or repeating pattern was established. Models that used a 4-cell neighbourhood ('Rook's move') instead of an 8-cell neighbourhood ('Queen's move'; Childress et al. 1996) only produced changes in patch geometry and not the underlying pattern of spatial dynamics. Results from 4-cell neighbourhood models are not presented.

\section{RESULTS}

\section{Mechanisms producing spatial patterns and dynamics}

Dependence on local conditions of the transitions in the patch cycle as described above produces particular kinds of static and dynamic spatial patterns. The translation of rules and local abundance thresholds into these patterns reveals potential mechanisms by which similar patterns may be produced in natural conditions. 
Spatial distributions of cells of different states rapidly converged toward static patterns for some combinations of rules and local abundance thresholds for state changes. The commonest configuration consisted of patches of escapes (state 2) and limpet aggregations (state 4). This pattern emerged when the rule for aggregation of limpets under a Fucus clump needed Fucus to be rare in adjacent cells (rule [1a] in this model) and the rule for disaggregation of limpets from the site of a former plant required limpets to be locally rare (rule [3a]). Under these conditions, when an area of Fucus escape (a state 2 cell) is almost surrounded by Fucus-free areas (state 4 cells in the stable patch pattern), as might be found at an extremity of a larger patch [Fig. 3a, condition (1)], limpet aggregation (transition from state 2 to 3 ) will occur in that area. If the area is not surrounded by other areas with Fucus plants, limpet aggregation will not occur [Fig. 3a, condition (2)]. Similarly, limpet aggregations on the sites of former plants (state 4) will not disperse (state 4 to 5) if surrounded by areas with other aggregations [Fig. 3a, condition (4)], but may do so if mostly surrounded by fucoid escapes with low densities of limpets [Fig. 3a, condition (3)]. This process results in the erosion of patches until resistant, larger-scale stable areas remain. Critical values for threshold local abundance of limpets and fucoids $\left(L_{C}=12\right.$ and $\left.F_{C}=5\right)$, below which patches are stable, are determined by the maximum possible 'connectedness' of cells at the extremities of a patch. Fig. 3a, condition (2) shows the smoothest possible vertex of such a patch. If patch erosion can occur in such a condition, then the patches will not persist.

Other configurations of rules and thresholds resulted in dynamically evolving patterns. Advancing waves appeared in some formulations with bands of cells in progressive states of the cycle arranged in sub-circular or other periodic structures. When the rule determining aggregation of limpets requires limpets to be locally common (rules [1] or [1b] and [4]; Fig. 4), 1-cellwide bands of cells in the same state appear for relatively high threshold values of local limpet abundance ( $L_{C}=8$ to 10 ). Cells in state 2 in such structures are, however, 2 cells wide. This is because cells at the leading edge of a band in state 2 , an escape [Fig. 3b, condition (2)], can only be 'invaded' by limpets in adjacent cells. At this edge the only cells around are those in which limpets are rare, so progress from state 2 to state 3 (aggregation) is impossible. At the trailing edge of the band [Fig. 3b, condition (1)], cells are adjacent to those in which aggregation has already occurred, so can 'draw upon' this locally high limpet density to progress through the cycle. Bands over 3 cells wide in (a) Rule [1a] $2 \rightarrow 3$ if $\Sigma f<F_{c}$, Rule [3a] $4 \rightarrow 5$ if $\Sigma l<L_{c}$

(1)

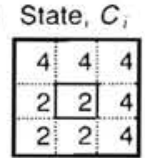

Fucoid abu
\begin{tabular}{|l|l|l|}
\hline 0 & 0 & 0 \\
\hline 1 & 1 & 0 \\
\hline 1 & 1 & 0 \\
\hline
\end{tabular}

$$
F_{c}=4
$$

$\therefore$ state 2 changes to state 3
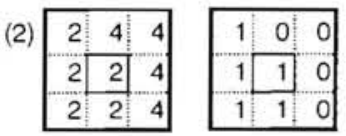

$$
F_{\mathrm{c}}=4
$$$$
\Sigma f=4
$$

$\therefore$ state 2 remains in state 2

(3) State, $C_{i} \quad$ Limpet abundance, 1 ,
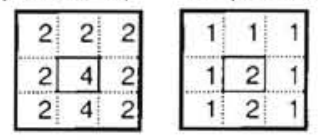

$$
\begin{aligned}
L_{c} & =10 \\
\Sigma I & =9 \\
\therefore \text { state } 4 & \text { does change to state } 5
\end{aligned}
$$

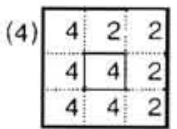

\begin{tabular}{|l|l|l|}
\hline 2 & 1 & 1 \\
\hline 2 & 2 & 1 \\
\hline 2 & 2 & 1 \\
\hline
\end{tabular}

$$
\begin{aligned}
\quad L_{c}=10 \\
\Sigma l=12 \\
\therefore \text { state } 4 \text { remains in state } 4
\end{aligned}
$$

(b) Rule [1b] $2 \rightarrow 3$ if $\Sigma />L_{c}$, Rule [4] Direction of wave propagation $\rightarrow$

$\begin{array}{lllllllllll}C_{i} & 4 & 3 & 2 & 2 & 1 & 5 & 4 & 3 & 2 & 2\end{array}$ Limpet abundance, $l_{i}$

(1)

\begin{tabular}{|l|l|l|l|lll|lll|}
2 & 2 & 1 & 1 & 0 & 0 & 2 & 2 & 1 & 1 \\
\hline 2 & 2 & 1 & 1 & 0 & 0 & 2 & 2 & 1 & 1 \\
\hline 2 & 2 & 1 & 1 & 0 & 0 & 2 & 2 & 1 & 1 \\
\hline 2 & 2 & 1 & 1 & 0 & 0 & 2 & 2 & 1 & 1 \\
\hline
\end{tabular}

(2)

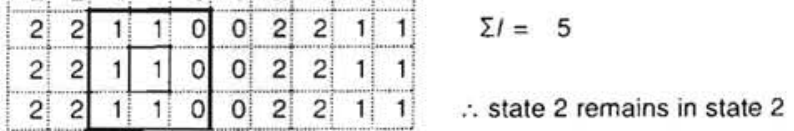

(c) Rule [1b] $2 \rightarrow 3$ if $\Sigma l>L_{c}$, Rule [4] Direction of wave propagation $\rightarrow$
$\begin{array}{lllllllllllll}C_{i} & 2 & 2 & 2 & 2 & 2 & 1 & 1 & 1 & 1 & 1\end{array} \quad L_{c}=5$
Limpet abundance, $I_{i}$$$
L_{c}=5
$$

\begin{tabular}{|lll|l|l|l|l|lll|}
\hline 1 & 1 & 1 & 1 & 1 & 0 & 0 & 0 & 0 & 0 \\
\hline 1 & 1 & 1 & 1 & 1 & 0 & 0 & 0 & 0 & 0 \\
\hline 1 & 1 & 1 & 1 & 1 & 0 & 0 & 0 & 0 & 0 \\
1 & 1 & 1 & 1 & 1 & 0 & 0 & 0 & 0 & 0 \\
\hline 1 & 1 & 1 & 1 & 1 & 0 & 0 & 0 & 0 & 0 \\
1 & 1 & 1 & 1 & 1 & 0 & 0 & 0 & 0 & 0 \\
1 & 1 & 1 & 1 & 1 & 0 & 0 & 0 & 0 & 0 \\
\hline
\end{tabular}

$$
\begin{aligned}
& L_{c}=7 \\
& \quad \Sigma I=11 \\
& \therefore \text { state } 2 \text { changes to state } 3 \\
& \Sigma I=5 \\
& \therefore \text { state } 2 \text { remains in state } 2
\end{aligned}
$$$$
\text { (1) } l=5
$$

$\therefore$ state 2 remains in state 2

(2) $I=8$

$\therefore$ state 2 changes to state 3

Fig. 3. Mechanisms of maintenance of (a) stable patches of Fucus escapes and limpet aggregations, and (b) and (c) waves of cells cycling through all states. Fates of the central cells in each 3 by 3 area are determined using the appropriate state transition rules by comparison of sums of abundance in adjacent cells $(\Sigma l, \Sigma f)$ with threshold values $\left(L_{C}, F_{C}\right)$ 

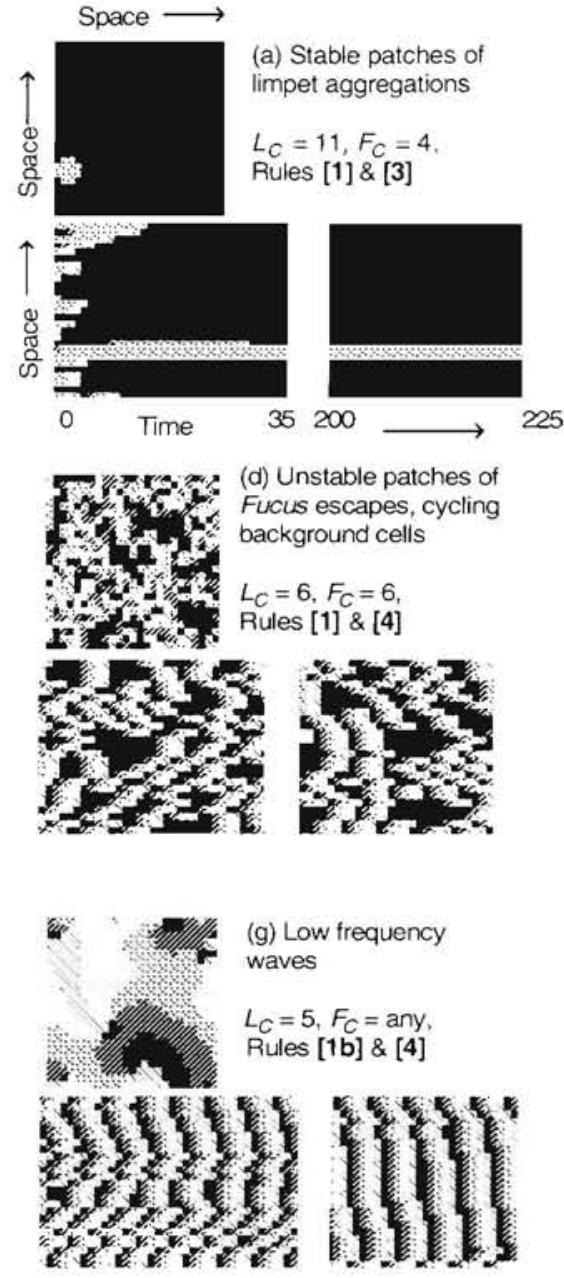

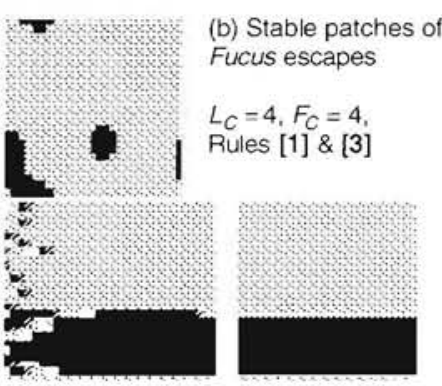

(e) Stable patches of
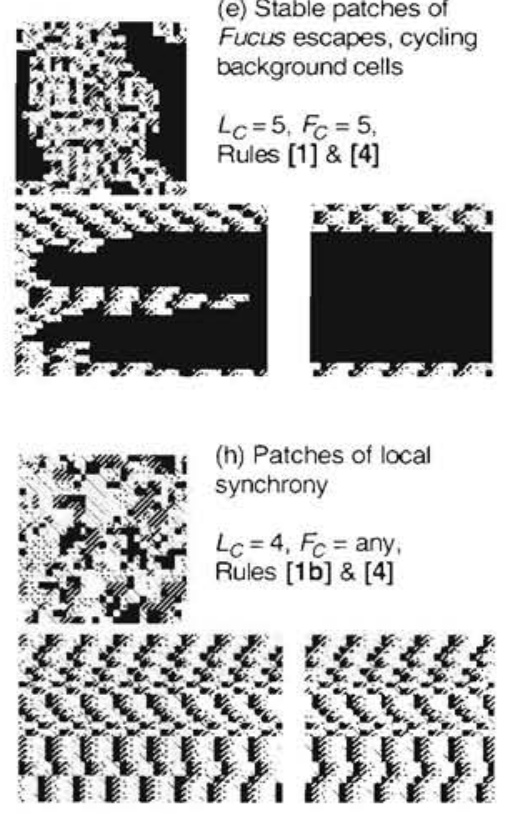

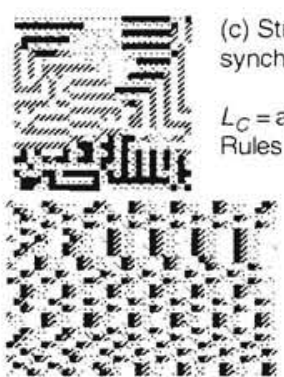

(c) Structured, synchronised patches

$L_{C}=$ any value, $F_{C}=2$, Rules [2] \& [3]
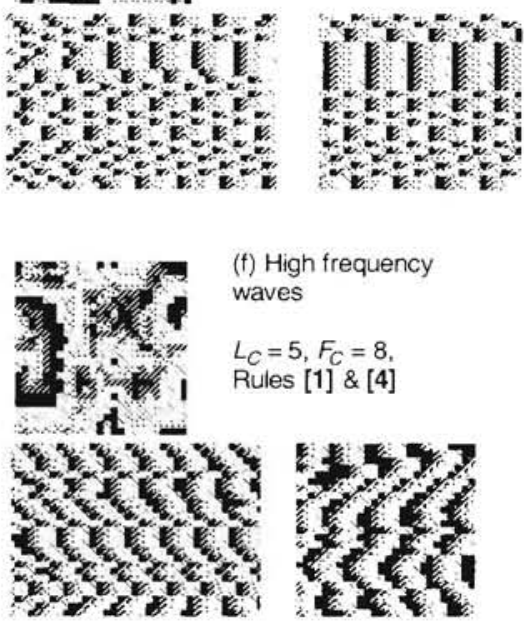

Fig. 4. Examples of spatial patterns and spatial dynamics shown by the model under combinations of different transition rules and thresholds of local abundance. Patterns (top left panel of each plot) are shown after 230 iterations in a 25 by 25 cell grid. Spatial dynamics are illustrated by sequential plots of the states of cells along the left hand edge of the matrix for iterations 0 to 35 (bottom left) and 200 to 225 (bottom right)

the same state occur when the threshold local limpet abundance is lower $\left(4<L_{C}<8\right.$; Fig. $\left.4 \mathrm{~g}\right)$. The propagation mechanism is similar, but aggregation can occur in escape (state 2) cells surrounded by other escapes [Fig. 3c, condition (2)]. Cells at the leading edge of a state 2 band remain in state 2 , so the bands slowly change position as the waves advance.

\section{Types of spatial patterns and dynamics}

The action of the above local mechanisms produced several recognisable types of spatial patterns with characteristic spatial dynamics (Fig. 4). Spatial dynamics are illustrated by space-time plots (Fig. 4) of the states of a single column of cells over time (Molofsky 1994, Rand 1994). Persistence of structures seen in the patterns can be assessed by reference to the plots of spatial dynamics.
Fig. $4 \mathrm{a}, \mathrm{b}, \mathrm{c}, \mathrm{e}, \mathrm{h}$ show persistent structures, while Fig. 4d, f, g show structures that evolve over time.

Without dependence of transitions on local conditions (rules [2] and [4]), cells cycled independently of each other (Fig. 5). With local dependence, some form of spatial self-organisation always appeared. The simplest form was a single state for all cells, followed by stable patterns of patches of alternate states and finally complex and dynamic spatial patterns. The most common outcome (Fig. 5) was fixation of the grid in one state, either Fucus escapes leading to total cover (state 2) or limpet aggregations (state 4). Variable mixtures of differently sized stable patches of Fucus escapes and limpet aggregations also occurred. These patches appeared as islands of limpet aggregations (state 4) (Fig. 4a), as a matrix of interconnected patches of both types, or as isolated patches of fucoid escapes (Fig. 4b). Steady-state conditions were approached by expan- 
Rules governing Fucus escapes: State 2 changes to 3 :
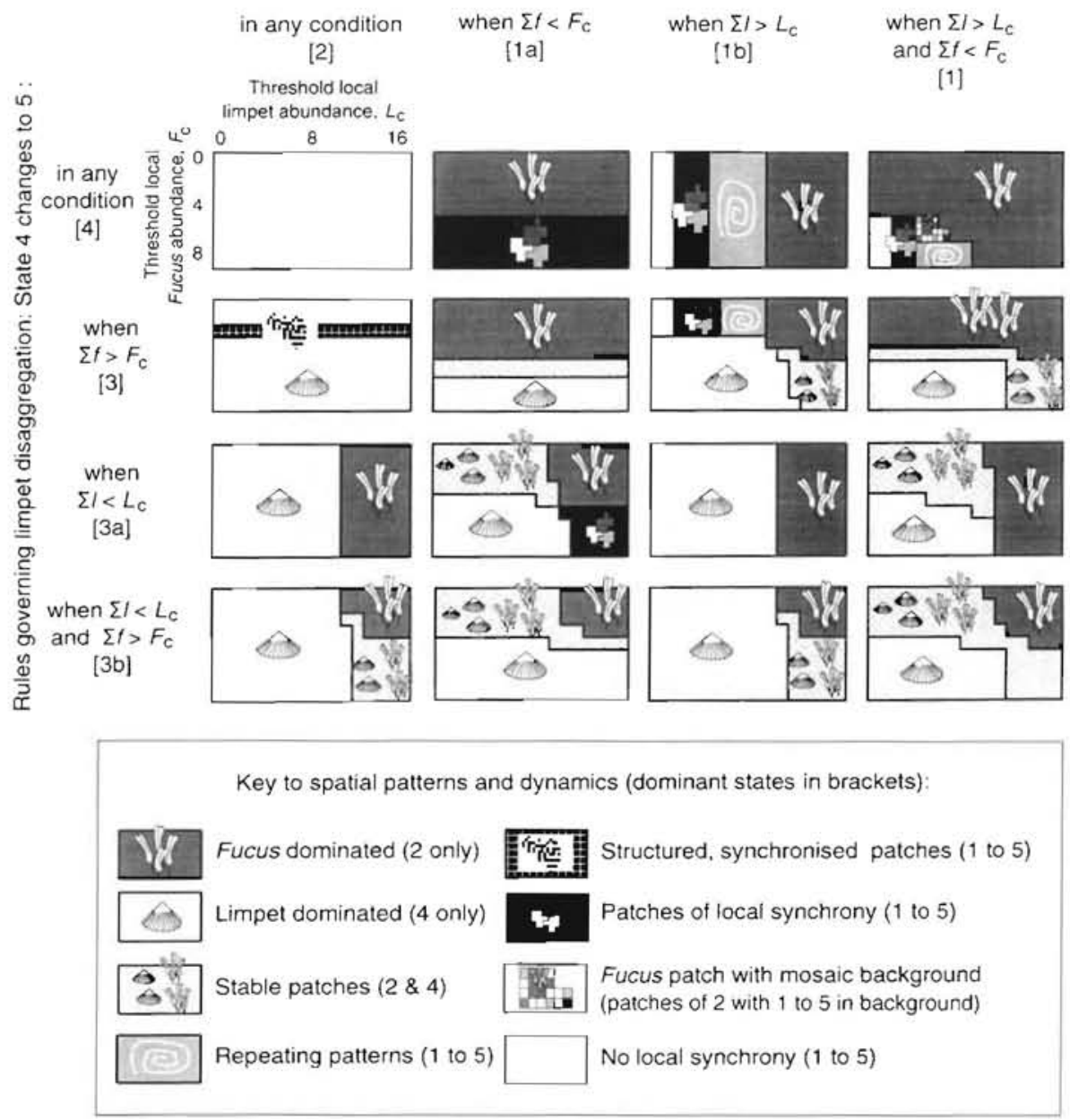

Fig. 5. Outcomes of cellular automata simulations as functions of state transition rules (Table 1) and thresholds of local abundance of limpets $\left(L_{\mathrm{C}}\right)$ and fucoids (F $F_{\mathrm{C}}$ : Eqs. 1 \& 2)

sion of groups of state 2 or state 4 cells, followed by the erosion of patches of the sub-dominant state.

Stable patterns also occurred in which some cells on the grid still cycled through the 5 states. A complex spatial structure appeared when disaggregation of limpets depended on local Fucus abundance (rules [2] and [3], $F_{C}=2$ ) in which adjacent cells within a patch were either in the same state or 2 steps out of phase with each other (Fig. 4c). In this case disaggregation of limpets (state 4 to state 5 ) only occurs when 2 or more adjacent cells are in the fucoid escape state (state 2). This produces the characteristic pattern of alternating bands of cells in the same state within a larger structure (Fig. 4c).

Stable spatial patterns were also seen when stabilised patches of cells in states 2 or 4 appeared in a matrix of cells cycling through all states (Fig. 4e). Stable patches of fucoid escapes occur because such escapes inhibit the aggregation of limpets onto new escapes at the patch edge. Cells on the edge of a patch where escapes occur are assimilated into the larger patch. The final type of spatially stable pattern was that in which small patches of cells began to cycle in synchrony with each other (Fig. 4 h). The most complex type of behaviour was that in which large-scale spatial structures of changing shapes evolved. One characteristic behaviour (Fig. 4f, g) involved waves of synchronised cells radiated from local foci, often forming spirals or subcircular structures. The waves consisted of narrow bands of synchronised cells, 1 to 2 cells wide (Fig. 4f), or as larger areas of synchrony (Fig. 4e). Another form of complex behaviour produced unstable patches of Fucus escapes (Fig. 4d), which expanded and contracted over short time scales.

Patterns of changes in abundance of the 3 community elements summed over the whole grid were characteristic of the observed patterns. Fixed patterns, either homogeneity or stable patches, rapidly reached stasis with either constant abundance of each type (Fig. $6 \mathrm{a}, \mathrm{b}, \mathrm{e}$ ) or with periodic changes between con- 
stant values (Fig. 6c, h). Structured, synchronised patches with alternate bands of cells produced global abundances of barnacles, limpets and fucoids which followed a 6-point cycle which approximated to a 3 point cycle (Fig. $6 \mathrm{c}$ ). This was produced as the 2 phases in each of 3 patch types (Fig. 4c) moved through the 5 states in turn, with cells remaining in state 4 for 2 time steps. Patches of locally synchronised cells (Fig, $4 \mathrm{~h}$ ) followed a 5-point cycle (Fig. 6h) as patches of cells moved from one state to the next with each time step.

Dynamic patterns produced either 5-point cycles of grid-scale abundance (Fig. 6f, g) or aperiodic fluctuations (Fig. 6d). Periodic changes in abundance reflected changes in state of large areas of cells in wavelike structures. Waves were synchronised with each other such that they met in the same state. As the wave of cells in the same state travelled out from the focus of the wave, larger areas were covered by that state. The
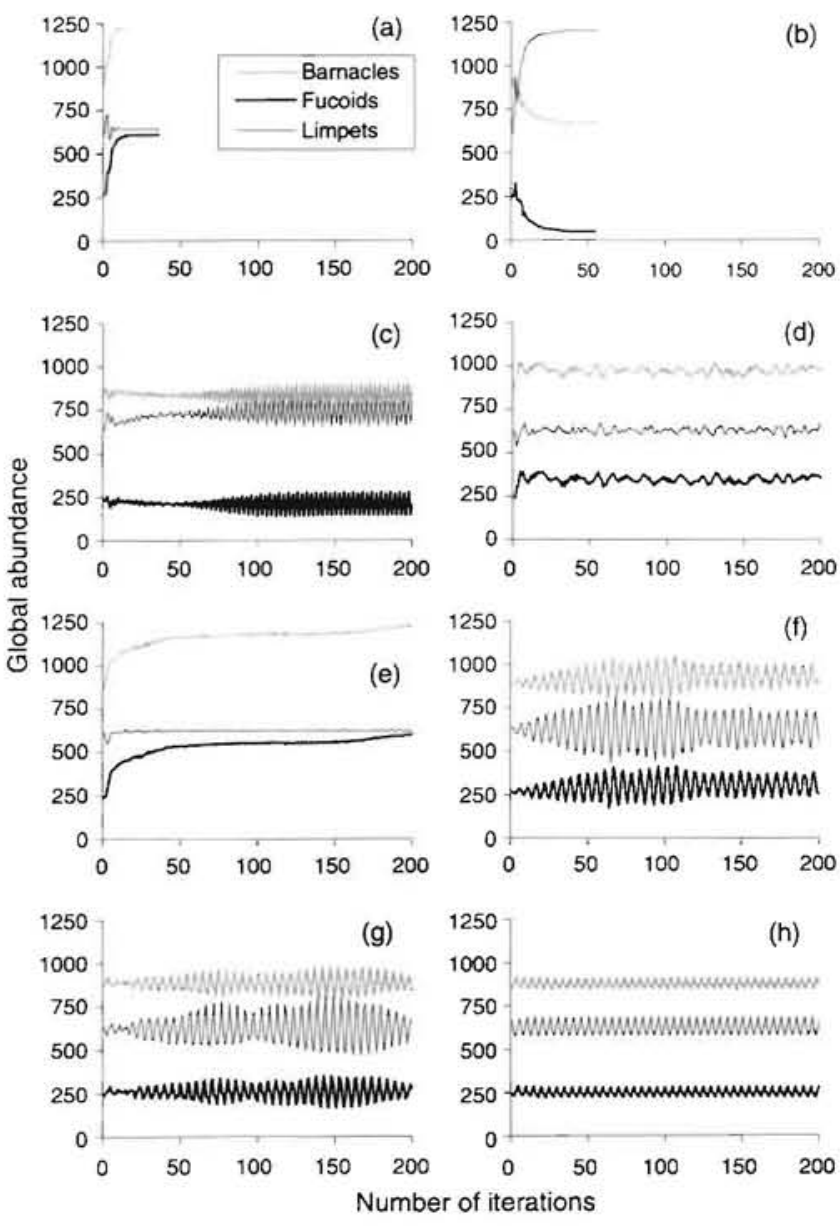

Fig. 6. Changes in grid-scale abundance of the 3 community elements in the model over 40 iterations in a 100 by 100 cell grid under different transition rules and thresholds of local abundance. Plots give the changes for the examples shown in Fig. 4
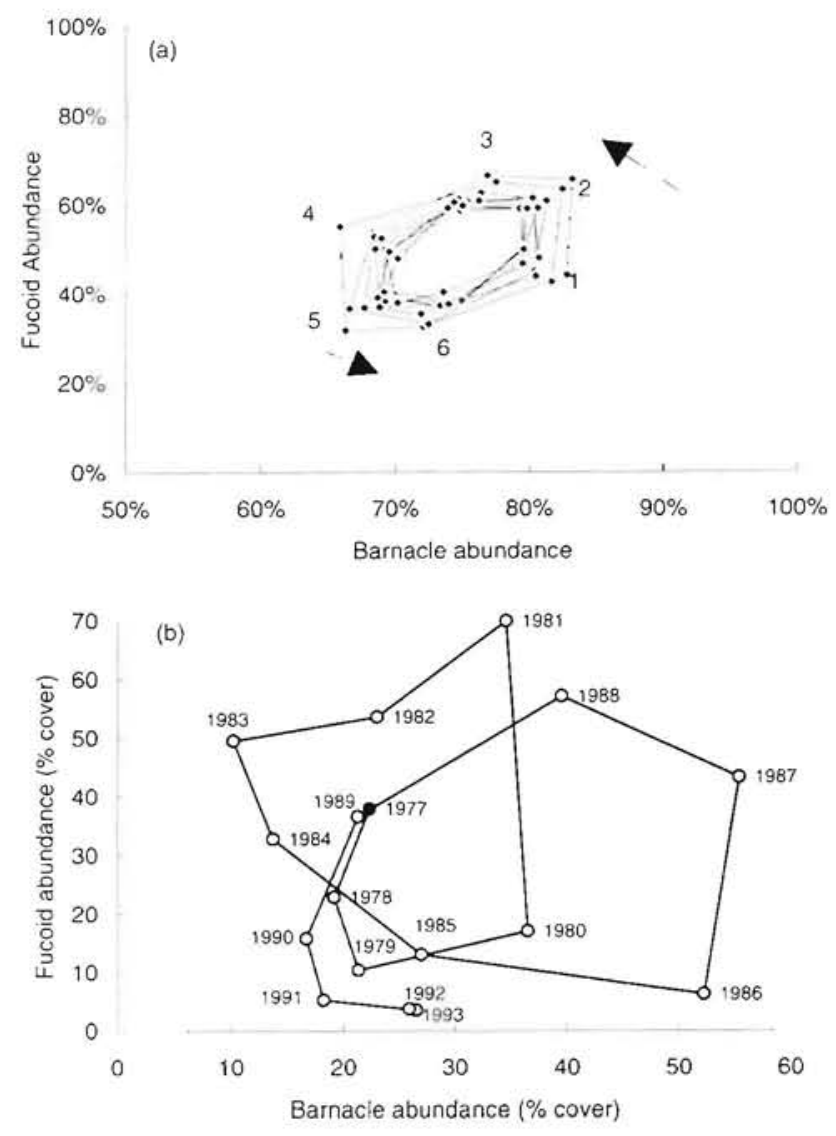

Fig. 7. (a) Cycling in grid-scale abundance of barnacles and fucoids (expressed as \% cover) for time steps 100 to 150 in the simulation shown in Figs. 4f \& 6f (cf. Hartnoll \& Hawkins 1985). Arrows show the direction of movement through the cycle. (b) Cycling in average yearly abundance of barnacles and fucoids in a $2 \mathrm{~m}$ by $1 \mathrm{~m}$ area in the mid-shore at Port $\mathrm{St}$. Mary Ledges, based on data shown in Fig. 1

phase of periodic grid-scale changes in the 3 community elements reflected that which is inherent in the basic patch cycle (see changing abundance scores for the 5 states in Table 1). Changes in fucoid abundance lagged behind those of barnacle abundance by 1 time step (Fig. 7a), while changes in limpet abundance followed those of the fucoids by a further time step. This cycling is also seen in the field data (Fig. 7b), albeit over a different range in abundance values. The aperiodic fluctuations in Fig. $6 \mathrm{~d}$ were due to the appearance and disappearance of small unstable patches of fucoids (Fig. 4d).

In all dynamic patterns the size of grid-scale changes compared with the maximum values for abundance decreased with increasing grid size. As the size of the grid approached that of the spatial patterns produced (e.g. spiral waves; Fig. 4f, g) all cells of the grid being in the same state at each interval becomes more likely. 


\section{Effects of different thresholds for local abundance and transition rules}

Stable homogeneity appeared in every combination of rules for aggregation and disaggregation of limpets (Fig. 5). Fixation in state 2 (Fucus escape) tended to occur when $F_{C}$ was low and when $L_{C}$ was high, while fixation in state 4 (limpets only) generally occurred when $L_{C}$ was low and when $F_{C}$ was high. Stable patches appeared when state transitions depended on both local limpet and local fucoid abundance (Fig. 5).

Complex CA behaviour only resulted from 3 combinations of rules (Fig. 5, rules [4] and [1b] or [1], rules [3] and [1b]) and was only seen at intermediate values of $L_{C}$ (Fig. 5).

\section{DISCUSSION}

By constructing models which incorporate rules for the spatial development of rocky shore communities, based on the aggregation and disaggregation of the principal herbivore, it has been possible to produce spatial patterns qualitatively similar to those observed in nature. Isolated patches of fucoids in a limpet-barnacle matrix are common in the mid- to upper shore at moderately exposed sites (Fig. 4b; Lewis 1964, Hartnoll \& Hawkins 1985). Clearings with limpets in a fucoid-dominated area occur low on the shore in moderately exposed conditions (Fig. 4a), and higher on the shore in sheltered conditions, while more extreme sheltered and exposed shores show fucoid and limpet dominance respectively. Other spatial patterns predicted by the model (e.g. Fig. 4c, e) seem more unlikely. The tendency of the deterministic model here to stabilise into one state (under conditions which seem likely) emphasises the importance of external stochastic factors in initiating the cycle via escapes. The importance of recruitment fluctuations in generating temporal variability on European rocky shores has long been appreciated (Fischer-Piette 1936, Southward \& Crisp 1954, Lewis 1976, Hawkins \& Hartnoll 1982a, Kendall et al. 1985) and has recently been re-emphasised with the advent of 'supply-side ecology' (Gaines \& Roughgarden 1985. Gaines et al. 1985).

In nature, the spatial dynamics of an ecological system like the Fucus-limpet-barnacle mosaic cycle depends on the underlying processes. The interactions of limpets and Fucus clumps show most of the properties of an 'activator-inhibitor' system (Kareiva 1990). Fucus clumps activate the aggregation of limpets that then inhibit the production of new clumps. When these systems occur with the inhibitor (limpet 'predator') dispersing more rapidly than the activator (Fucus 'prey'), fixed spatial patterns can occur (a stable fucoid-limpet mosaic), as happens for many rule and parameter sets in this model. Similar fixed patterns are produced in models of animal colour patterns and in annealing processes (Ermentrout \& Edelstein-Keshet 1993).

Fixed patterns, including fixation of the whole grid in a single state, were produced for most of the combinations of transition rules and local thresholds in the Fucus-limpet model. However, a wide range of dynamic spatial patterns were predicted for a small subset of rule combinations which were critically dependent on threshold values. Spiral waves and other sub-circular periodic structures of some rule sets have also been observed in spatial models of parasitoids and their hosts (Hassell et al. 1991, Solé et al. 1992) and predator-prey systems (Comins et al. 1992, Rand 1994). However outlandish these patterns may appear, many biological systems are characterised by regular spatial patterns which seem be self-organised (Rohani et al. 1997), and which may persist despite some degree of environmental heterogeneity or stochastic disturbance (Ruxton \& Rohani 1996).

Although the mechanisms producing the spatial dynamics we derive here seem complex, similar phenomena have been observed in natural conditions on rocky shores. Waves of limpets advancing into remaining stands of macroalgae were seen on some shores 4 to $5 \mathrm{yr}$ after the major disruption caused by dispersant application following the Torrey Canyon oil spill in southwest England in 1967 (Southward \& Southward 1978, Hawkins \& Southward 1992). Littorinids advance in waves into patches of ephemeral green algae (R. L. Vadas pers. comm.) in the early spring in the low intertidal zone on the coast of Maine, USA. Nucella lapillus, a predatory gastropod, may also form wave-fronts onto patches of its prey species (Hughes \& Burrows 1993). Whether similar processes can generate large-scale patches of limpet aggregations or Fucus plants that are resistant to invasion by the other, however, is not yet known.

Photographic observations at Port St. Mary Ledges on the Isle of Man, where the model was originally developed, suggest that the whole shore goes through periods of denser fucoid cover (mid 1980s) followed by barer periods (1990 to 1992). Grazing activity by limpets prevents escapes by fucoids in the limpet-barnacle matrix on these shores (Jones 1948, Lodge 1948, Hawkins 1981a, b), affecting abundance at the wholeshore level. Thus, processes operating on the wholeshore scale (10 to $100 \mathrm{~m}$ ) are affected by those operating at the more local scale (1 to $2 \mathrm{~m}$ ). Our current hypothesis is that the grid-scale dynamics depend upon the balance of fucoid escapes versus limpet grazing. In recent years the shore has been bare with little barnacle recruitment, which has probably reduced the 
likelihood of escapes. Changes on a smaller scale tend to be larger and depend on the local interactions of limpets and clumps of Fucus.

Models of predator-prey systems have shown that stability can be achieved for parameter sets which would normally lead to extinction of prey and/or predators when predator dispersal is limited through asynchronous changes in different parts of the lattice (Kareiva 1990). For certain types of local dependence in the CA models, grid-scale cycling in the abundance of major community elements (Figs. $6 \&$ 7) can be driven purely by local spatial dependence, providing that the scale of averaging is not too large. Translation from local- to grid-scale effects in the model is achieved through synchronisation of patch cycling in adjacent areas. This mechanism may be the only way in which grid-scale cycling could evolve solely from local interactions. The most likely alternative is that changes at the larger scale are driven by processes acting at that scale, such as the arrival of settling larvae (e.g. Hawkins \& Hartnoll 1982a, Kendall et al. 1985) or mass mortalities from pollution events (limpets, death from surfactants used to disperse oil spills; Southward \& Southward 1978). It is therefore important to identify the range of scales over which the effects of particular ecological processes are important (the 'domain of scale', Wiens 1989; 'characteristic length scale', Keeling et al. 1997). The models produced here have deliberately considered only small-scale processes to predict consequences at larger scales.

The biological determinants of patchiness considered here must act together with physical causes. Direct physical effects include the production of clearances through wave stress, damage by floating logs (Dayton 1971), ice scour (Bergeron \& Bourget 1986) or wave-borne rocks (Shanks \& Wright 1986). Localised physical conditions may also produce patchiness indirectly through effects on structuring organisms. Certain physical conditions may favour matrix-building species, such as barnacles (Barnes \& Powell 1950) or mussel beds (Paine \& Levin 1981), while the presence of crevices offers refuges for mobile predators such as predatory gastropods (Menge 1978, Fairweather 1988b) or mobile herbivores (top shore littorinids: Raffaelli \& Hughes 1978). Small-scale differences in slope and aspect or water drainage may also allow delicate species to persist in otherwise too harsh environments (Wethey 1984). It is likely that climate change may alter physical factors including stormgenerated disturbance (e.g. Shanks \& Wright 1986) as well as influencing the likelihood of escapes by affecting reproductive output, early growth and survival.

The current formulation of the model can only produce qualitative predictions of the general nature of the dynamics of spatial patterns in Fucus-limpet-barnacle mosaics on rocky shores. Detailed comparisons of predictions with field data and further analysis of the dynamics of pattern have not been attempted here, because of their essentially qualitative nature. Analysis of field patterns (Johnson et al. 1997) and repeated mapping of the same areas (M. P. Johnson unpubl.) has provided the necessary transition probabilities for probabilistic cellular automata which generate directly testable predictions. The likelihood of Fucus escapes might be predicted as a function of local herbivore density, for example. Criteria for local dependence of aggregation and disaggregation of limpets under Fucus clumps need to be assessed. The Fucus-limpet-barnacle patch mosaic offers a particularly good opportunity for a thorough analysis of the dynamics of a spatially extended ecosystem, being both easily accessible and monitored and with relatively well understood structuring processes. A spatially resolved time series of the dynamics of patches on a larger scale than Hawkins \& Hartnoll's (1983a) study of a $2 \mathrm{~m}$ by $1 \mathrm{~m}$ area may permit the application of recent advances in the analysis of spatial dynamics of models (Keeling et al. 1997) to show the characteristic length scales at work in the real system. Experiments are needed in which limpets are excluded from the areas analogous to cells in the model. Subsequent events in the adjacent areas when the Fucus patches have matured in the exclusion area could test the assumptions of spatial dependence and the scales over which it operates.

The relative roles of physical and biological determinants of patchiness are largely unknown. Physical causes might be expected to dominate in harsh environments, or where the substratum offers a heterogeneous physical environment (e.g. boulder shores; Sousa 1979). Biological causes may be more important where the substratum is homogeneous, such as on the smooth gently shelving limestone of Port St. Mary Ledges on the Isle of Man. The amount of spatial heterogeneity (cracks, crevices) will affect the likelihood of patch cycling. In smooth areas, fucoids provide a biologically generated refuge and act as attractants for juvenile and adult limpets. In crevices or rough areas, physically provided refuges are available and patches will tend to be static. Finally, the relative roles of smallscale $(1$ to $10 \mathrm{~m})$ and large-scale $(100 \mathrm{~m}$ to $10 \mathrm{~km})$ ecological processes in the production of patterns at a range of scales need to be assessed.

Acknowledgements. This work was initially supported by research grant GR3/8479A from the Natural Environment Research Council. Further development was supported by NERC Special Topic grant GST/02/983 and a EUROROCK Module $\mathrm{C}$ workshop funded by a MAST III grant. 


\section{LITERATURE CITED}

Archambault P, Bourget E (1996) Scales of coastal heterogeneity and benthic intertidal species richness, diversity and abundance. Mar Ecol Prog Ser 136:111-121

Barnes H, Powell HT (1950) The development, general morphology and subsequent elimination of barnacle populations, Balanus crenatus and Balanus balanoides after a heavy initial settlement. J Anim Ecol 19:175-179

Barnes H, Topinka JA (1969) Effect of the nature of the substratum on the force required to detach a common littoral alga. Am Zool 9:753-758

Bergeron P, Bourget E (1986) Shore topography and spatial partitioning of crevice refuges by sessile epibenthos in an ice disturbed environment. Mar Ecol Prog Ser 28:129-145

Burrows EM, Lodge SM (1950) Note on the interrelationships of Patella, Balanus and Fucus on a semi-exposed coast. Rep Mar Biol Stn Port Erin 62:30-34

Caffey HM (1985) Spatial and temporal variation in settlement and recruitment of intertidal barnacles. Ecol Monogr 55:313-332

Childress WM, Rykiel EJ, Forsythe W, Li BL, Wu HI (1996) Transition rule complexity in grid-based automata models. Landscape Ecol 11:257-266

Comins HN, Hassel MP, May RM (1992) The spatial dynamics of host-parasitoid systems. J Anim Ecol 61:735-748

Dayton PK (1971) Competition, disturbance and community organisation: the provision and subsequent utilisation of the space in a rocky intertidal community. Ecol Monogr 41:351-389

Dunkerly DL (1997) Banded vegetation: survival under drought and grazing pressure based on a simple cellular automaton model. J Arid Environ 35:419-428

Ermentrout GB, Edelstein-Keshet L (1993) Cellular automata approaches to biological modelling. J Theor Biol 160:97-133

Fairweather PG (1988a) Predation creates haloes of bare space among prey on rocky seashores in New South Wales. Aust J Ecol 13:401-409

Fairweather PG (1988b) Movements of intertidal whelks (Morula marginalba and Thais orbita) in relation to availability of prey and shelter. Mar Biol 100:63-68

Fischer-Piette E (1936) Études sur la biogeographie des deux rives de la Manche. J Linn Soc 15:181-272

Gaines SD, Brown S, Roughgarden J (1985) Spatial variation in larval concentration as a cause of spatial variation in settlement for the barnacle, Balanus glandula. Oecologia $67: 267-272$

Gaines SD, Roughgarden J (1985) Larval settlement rate: a leading determinant of structure in ecological communities of the marine intertidal zone. Proc Natl Acad Sci USA 82:3707-3711

Hartnoll RG, Hawkins SJ (1985) Patchiness and fluctuations on moderately exposed rocky shores. Ophelia 24:53-63

Hartnoll RG, Wright JR (1977) Foraging movements and homing in the limpet Patella vulgata L. Anim Behav 25: $806-810$

Hassel MP, Comins HN, May RM (1991) Spatial structure and chaos in insect population dynamics. Nature (Lond) 353 $255-258$

Hawkins SJ (1981a) The influence of Patella grazing on the fucoid/barnacle mosaic on moderately exposed rocky shores. Kiel Meeresforsch 5:537-543

Hawkins SJ (1981b) The influence of season and barnacles on the algal colonization of Patella vulgata exclusion areas. $J$ Mar Biol Assoc UK 61:1-15

Hawkins SJ (1983) Interactions of Patella and macroalgae with settling Semibalanus balanoides (L.). J Exp Mar Biol
Ecol 71:55-72

Hawkins SJ, Hartnoll RG (1982a) Settlement patterns of Semibalanus balanoides (L.) in the Isle of Man (19771981). J Exp Mar Biol Ecol 62:271-283

Hawkins SJ, Hartnoll RG (1982b) The influence of barnacle cover on the numbers, growth and behaviour of Patella vulgata on a vertical pier. J Mar Biol Assoc UK 62: 855-867

Hawkins SJ, Hartnoll RG (1983a) Changes in a rocky shore community: an evaluation of monitoring. Mar Environ Res 9:131-181

Hawkins SJ, Hartnoll RG (1983b) Grazing of intertidal algae by marine invertebrates. Oceanogr Mar Biol Annu Rev 21 . $195-282$

Hawkins SJ, Hartnoll RG, Kain JM, Norton TA (1992) Plantanimal interactions on hard substrata in the north-east Atlantic. In: John DM, Hawkins SJ, Price JH (eds) Plantanimal interactions in the marine benthos. Oxford University Press, Oxford, p 1-32

Hawkins SJ, Southward AJ (1992) The Torrey Canyon oil spill: recovery of rocky shore communities. In: Thayer GW (ed) Restoring the national marine environment. Maryland Sea Grant College, University of Maryland, College Park, p 583-619

Hendry RJ, McGlade JM (1995) The role of memory in ecological systems. Proc R Soc Lond B Biol Sci 259:153-159

Hughes RN, Burrows MT (1993) Predatory behaviour of the intertidal snail, Nucella lapillus, and its effects on community structure. In: Kawanabe $\mathrm{H}$, Cohen JE, Iwasaki K (eds) Mutualism and community organisation: behavioural, theoretical and food web approaches. Oxford University Press, Oxford, p 63-83

Jeltsch F, Milton SJ, Dean WRJ, van Rooyen N (1996) Tree spacing and coexistence in semiarid savannas. J Ecol 84 583-595

Jeltsch F, Wissel C (1994) Modelling dieback phenomena in natural forests. Ecol Model 75/76:111-121

Johnson M, Burrows MT, Hartnoll RG, Hawkins SJ (1997) Spatial structure on moderately exposed rocky shores: patch scales and the interactions between limpets and algae. Mar Ecol Prog Ser 160:209-215

Jones NS (1948) Observations and experiments on the biol. ogy of Patella vulgata at Port St Mary, Isle of Man. Proc Trans Liverpool Biol Soc 56:60-77

Kareiva P (1990) Population dynamics in spatially complex environments: theory and data. Philos Trans Roy Soc Lond Biol Sci 330:175-190

Keeling MJ, Mezic 1, Hendry RJ, McGlade J, Rand DA (1997) Characteristic length scales of spatial models in ecology via fluctuation analysis. Philos Trans R Soc Lond Biol Sci 352:1589-1601

Kendall MA, Bowman RS, Williamson P, Lewis JR (1985) Annual variation in recruitment of Semibalanus balanoides on the North Yorkshire coast 1969-1981. J Mar Biol Assoc UK 65:1009-1030

Lewis JR (1964) The ecology of rocky shores. English Universities Press, London

Lewis JR (1976) Long-term ecological surveillance: practical realities in the rocky littoral. Oceanogr Mar Biol Annu Rev 14:371-390

Lewis MA (1994) Spatial coupling of plant and herbivore dynamics: the contribution of herbivore dispersal to transient and persistent 'waves' of damage. Theor Popul Biol 45:277-312

Lodge SM (1948) Algal growth in the absence of Patella on an experimental strip of foreshore, Port St Mary, Isle of Man. Proc Trans Liverpool Biol Soc 56:78-83 
Lubchenco J (1983) Littorina and Fucus: effects of herbivores, substratum heterogeneity and plant escapes during succession. Ecology 64:1116-1124

Mangel M (1994) Spatial patterning in resource exploitation and conservation. Philos Trans Roy Soc Lond Biol Sci 343: 93-98

Menge BA (1978) Predation intensity in a rocky intertidal community. Oecologia (Berl) 34:1-16

Menge BA (1991) Relative importance of recruitment and other causes of variation in rocky intertidal community structure. J Exp Mar Biol Ecol 146:69-100

Molofsky J (1994) Population dynamics and pattern formation in theoretical populations. Ecology 75:30-39

Morrisey DJ, Howitt L, Underwood AJ, Stark JS (1992) Spatial variation in soft-sediment benthos. Mar Ecol Prog Ser 81 . $197-204$

Paine RT, Levin SA (1981) Intertidal landscapes: disturbance and the dynamics of pattern. Ecol Monogr 51 . $145-178$

Pickett STA, White PS (eds) (1985) The ecology of natural disturbance and patch dynamics. Academic Press, London

Raffaelli DG. Hughes RN (1978) The effect of crevice size and availability on populations of Littorina rudis and Littorina neritoides. J Anim Ecol 47:71-83

Rand DA (1994) Measuring and characterizing spatial patterns, dynamics and chaos in spatially extended dynamical systems and ecologies. Philos Trans R Soc Lond Math Phys Sci A 348:497-514

Rohani P, Lewis TJ, Grunbaum D, Ruxton GD (1997) Spatial self-organization in ecology: pretty patterns or robust reality? Trends Ecol Evol 12:70-74

Rohani P, Miramontes O (1995) Host-parasitoid metapopulations: the consequences of parasitoid aggregation on spatial dynamics and searching efficiency. Proc R Soc Lond B Biol Sci 260:335-342

Ruxton GD, Rohani P (1996) The consequences of stochasticity for self-organized spatial dynamics, persistence and coexistence in spatially extended host-parasitoid communities. Proc Roy Soc Lond B Biol Sci 263:625-631

Shanks AL, Wright WG (1986) Adding teeth to wave action the destructive effects of wave borne rocks on intertidal organisms. Oecologia 69:420-428

Sherratt JA, Egan BT, Lewis MA (1997) Oscillations and chaos

Editorial responsibility: Otto Kinne (Editor)

Oldendorf/Luhe, Germany behind predator-prey invasion: mathematical artifact or ecological reality? Philos Trans R Soc Lond Biol Sci 352 21-38

Shorrocks B, Swingland IR (eds) (1990) Living in a patchy environment. Oxford University Press, Oxford

Solé RV, Valls J، Bascompte J (1992) Spiral waves, chaos and multiple attractors in lattice models of interacting populations. Phys Lett A 166:123-128

Sousa WP (1979) Disturbance in marine intertidal bouider fields: the nonequilibrium maintenance of species diversity. Ecology 60:1225-1239

Southward AJ (1953) The ecology of some rocky shores in the Isle of Man. Proc Trans Liverpool Biol Soc 59:1-50

Southward AJ (1956) The population balance between limpets and seaweeds on wave-beaten rocky shores. Rep Mar Biol Stn Port Erin 67:20-29

Southward AJ (1964) Limpet grazing and the control of vegetation on rocky shores. In: Crisp DJ (ed) Grazing in terrestrial and marine environments. Blackwell, Oxford, p 265-273

Southward AJ, Crisp DJ (1954) Recent changes in the distribution of the intertidal barnacles Chthamalus stellatus Poli and Balanus balanoides L. in the British Isles. J Anim Ecol 23:163-177

Southward AJ, Southward EC (1978) Recolonization of rocky shores in Cornwall after use of toxic dispersants to clean up the Torrey Canyon spill. J Fish Res Bd Can 35 $682-706$

Underwood AJ, Chapman MG (1996) Scales of spatial patterns of distribution of intertidal invertebrates. Oecologia 107:212-224

van der Laan JD, Lhotka L, Hogeweg P (1995) Sequential predation: a multi-model study. J Theor Biol 174:149-167

Wethey DS (1984) Sun and shade mediate competition in the barnacles Chthamalus and Semibalanus: a field experiment. Biol Bull (Woods Hole) 167:176-185

Wiens JA (1989) Spatial scaling in ecology. Funct Ecol 3 : 385-397

Wolfram S (1986) Theory and applications of cellular automata. World Scientific, Singapore

Zhou G, Liebhold AM (1995) Forecasting the spatial dynamics of gypsy moth outbreaks using cellular transition models. Landscape Ecol 10:177-189

Submitted: January 12, 1996; Accepted: March 30, 1998 Proofs received from author(s): May 25, 1998 